\title{
PEMETAAN PENGARUH TINGKAT PENDIDIKAN, PENDAPATAN DAN USIA KAWIN TERHADAP JUMLAH ANAK LAHIR HIDUP DI KELURAHAN KOTALAMA, KECAMATAN KEDUNG KANDANG
}

\section{Mapping Effects Of Education Level, Income And Age Of Marriage On The Number Of Children Born Allive In Kotalama Village, Kedungkandang District}

\author{
Satrio Putro Utomo ${ }^{1 *}$, Udin Kurniawan Aziz ${ }^{2}$ \\ ${ }^{1}$ Jurusan Geografi, Fakultas Ilmu Sosial, Universitas Negeri Malang \\ ${ }^{2}$ Peneliti Madya Perwakilan BKKBN Jawa Timur \\ *email: satriokecee@gmail.com
}

\begin{abstract}
The high population is due to the high number of children born into families. Number of children born alive is the number of children born in the living conditions of an EFA. The large number of children born alive is influenced by demographic and non-demographic factors.The fertility level can be influenced by factors of the mother's last education, total family income and age of the mother's first marriage. This study aims to determine the effect of variables of education, income and age of first marriage. After that, a map is drawn to make it easier to provide information. Data analysis uses multiple linear regression. The results showed that total family income and age of first marriage affected the number of children born alive with sig values of 0.02 (income) and 0.00 (age of first marriage) $<\alpha$ $=0.5$, while maternal education had no influence with sig value $0.62>\alpha=0.5$. The average number of children born alive in Kotalama is 2.46. The conclusion was that the level of mother's education had no effect on the number of children and there was an effect of total family income and age of first wife's marriage on the number of children.
\end{abstract}

Keywors: Number of Children Born Live, Education, Income, Age of First Marriage and Mapping

\begin{abstract}
Abstrak
Jumlah penduduk yang tinggi disebabkan oleh tingginya jumlah anak yang lahir dalam keluarga. Jumlah anak lahir hidup merupakan banyaknya anak yang dilahirkan dalam kondisi hidup yang dimiliki PUS (Pasangan Usia Subur). Banyaknya jumlah anak lahir hidup dipengaruhi oleh faktor demografi dan faktor non demografi. Tingkat fertilitas dapat dipengaruhi oleh faktor pendidikan terakhir ibu, pendapatan total keluarga dan usia kawin pertama ibu. Penelitian ini bertujuan untuk mengetahui pengaruh variabel pendidikan, pendapatan dan usia kawin pertama terhadap jumlah anak lahir hidup di kelurahan kotalama, Kecamatan Kedung kandang. Dalam penelitian ini, menggunakan metode kuantitatf yaitu proses penggalian informasi yang diwujudkan dalam bentuk angka-angka yang diolah secara statistik, kemudian dijabarkan dalam bentuk peta. Subjek penelitian ini adalah ibu yang berusia produktif Analisis data menggunakan regresi linier berganda. Hasil penelitian menunjukan bahwa pendapatan total keluarga dan usia kawin pertama berpengaruh terhadap jumlah anak yang dilahirkan hidup dengan nilai sig 0,02 (pendapatan) dan 0,00 (usia kawin pertama) $<\alpha=0,5$, sedangkan pendidikan ibu tidak memiliki pengaruh dengan nilai sig $0,62>\alpha=0,5$. Rata-rata jumlah anak lahir hidup Kelurahan Kotalama sebesar 2,46. Diperoleh kesimpulan, bahwa tingkat pendidikan ibu tidak berpengaruh tergahadap jumlah anak, dan terdapat pengaruh pada pendapatan total keluarga dan usia kawin pertama istri terhadap jumlah anak.
\end{abstract}

Kata kunci: Jumlah Anak Lahir Hidup, Pendidikan, Pendapatan, Usia Kawin Pertama dan Pemetaan

\section{PENDAHULUAN}

Masalah utama yang dihadapi oleh negara yang berkembang tidak hanya masalah ekonomi, namun pertumbuhan penduduk yang tinggi juga menjadi masalah bagi sebagian negara yang berkembang termasuk Indonesia. Berdasarkan Sensus Penduduk tahun 2010, jumlah penduduk Indonesia mengalamai kenaikan dari 237 juta 
pada tahun 2010 menjadi 265 juta pada tahun 2018 (BPS, 2018).

Pertumbuhan penduduk di Indonesia dipengaruhi oleh beberapa faktor, yaitu fertilitas, mortalitas dan migrasi. Fertilitas berkaitan dengan kelahiran anak, mortalitas berkaitan dengan kematian bayi, sedangkan migrasi berkaitan dengan penduduk yang berpindah. Tingkat fertilitas yang tinggi, luasnya negara kepulauan dan tidak meratanya persebaran penduduk membuat Indonesia mengalami berbagai permasalahan terkait kependudukan. Permasalahan penduduk tersebut berupa permasalahan demografis dan non demografis. Permasalahan demografis yaitu besarnya jumlah penduduk, tingginya tingkat pertumbuhan penduduk dan persebaran penduduk yang tidak merata. Sedangkan permasalahan non demografis yaitu rendahnya tingkat kesehatan penduduk, rendahnya tingkat pendidikan serta banyaknya jumlah penduduk miskin (Nisak, 2019)

Pertumbuhan penduduk Indonesia yang tinggi menyebabkan tingginya jumlah penduduk. Jumlah penduduk Indonesia pada tahun 2017 sebesar 264.000.000 jiwa sehingga menempati urutan ke 4 di dunia setelah Republik Rakyat Cina (RRC), India, dan Amerika Serikat. Crude Birth Rate (CBR) atau angka kelahiran kasar di Indonesia mencapai 19 per 1000 penduduk, sedangkan Total Fertility Rate (TFR) atau angka kelahiran total mencapai angka 2,4 kelahiran per wanita. Angka tersebut lebih tinggi dibandingkan Provinsi Jawa Timur, yang memiliki CBR sebesar 13,3 per 1000 penduduk dan TFR sebesar 1,9 kelahiran per wanita dengan jumlah penduduk sebesar 39.075.152 jiwa (BKKBN, 2016)

Penduduk Kota Malang tahun 2017 sebagian besar adalah usia produktif, yaitu sebesar 625.812 jiwa atau 72,65 persen dari total penduduk. Sedangkan penduduk usia muda $(0-$ 14 tahun) berjumlah 186.666 jiwa (21,67 persen) dan penduduk usia 60 keatas sebesar 48.936 jiwa (5,68 persen). Rasio ketergantungan total penduduk Kota Malang pada tahun 2017 adalah 37,65 persen, didapatkan berdasarkan kelompok umur tidak produktif dibagi dengan kelompok umur produktif (Kota Malang) kemudian dibagi dengan 100. Angka ini berarti bahwa setiap 100 penduduk usia produktif (usia kerja) mempunyai beban tanggungan sebanyak 38 orang yang belum produktif dan dianggap tidak produktif lagi. Dengan rasio beban ketergantungan sebesar 37,65 ini menunjukkan bahwa di Kota Malang sudah memasuki masa Bonus Demografi. Bonus Demografi terjadi jika rasio beban ketergantungan dibawah 50, dengan prosentase usia produktif lebih dari 66,67 persen dan usia usia tidak produktif lebih rendah dari 33,33 persen. Pada masa ini merupakan potensi yang sangat baik untuk pemanfaatan sumber daya manusia pada usia produktif pada kegiatan ekonomi. Pada tahun 2016, CBR Kota Malang adalah sebesar 16 per 1000 penduduk, artinya terjadi kelahiran 16 untuk setiap 1000 penduduk. Angka ini cenderung stagnan selama 5 tahun terakhir. Sedangkan nilai TFR Kota Malang yaitu sebesar 2,09. (GDPK, 2018)

Kota Malang belum terjadi pemerataan penduduk, hal ini dapat dilihat dari adanya kesenjangan tingkat kepadatan penduduk antar kecamatan. Di satu sisi ada kecamatan yang tingkat kepadatannya di atas $10.000 / \mathrm{Km}^{2}$ namun di sisi lain ada yang kurang dari $5.000 \mathrm{jiwa} / \mathrm{km}^{2}$ (Kecamatan Kedungkandang Dalam Angka 2018).

Berdasarkan permasalahan tersebut, Kelurahan Kotalama merupakan salah satu daerah yang memiliki pertumbuhan penduduk yang tinggi. Kelurahan Kotalama merupakan salah satu Kelurahan yang berada Kecamatan Kedungkandang Kota Malang. Kecamatan Kedungkandang pada tahun 2016 memiliki jumlah kelahiran mencapai 2670 jiwa dan pertumbuhan penduduk Kecamatan Kedungkandang mencapai 1.25 dari 174.477 pada 2010 menjadi 190.274 pada 2017. Selain itu Kecamatan Kedungkandang persentase usia perkawinan pertama tertinggi sebesar $27,36 \%$. Terutama perkawinan pertama pada kelompok umur di bawah 20 tahun, presentasenya sebesar $50,39 \%$. Kotalama memiliki jumlah usia perkawinan pertama tertinggi pada tahun 2016 dengan total 125 orang (Badan Keluarga Berencana dan Pemberdayaan Masyarakat Kota Malang, 2016).

Kelurahan Kotalama memiliki kepadatan penduduk paling besar dari 12 kelurahan yang ada di Kecamatan Kedungkandang sebesar $46.489 / \mathrm{km}^{2}$ dan persentase penduduk nya mencapai $16,13 \%$ sebesar 30.683 jiwa pada 2017. Angka tersebut terdiri atas 15.431 jiwa laki - laki dan 15.252 jiwa perempuan. Selain itu angka kelahiran kasar (CBR) Kelurahan Kotalama yaitu sebesar 30,7 yang artinya setiap 1000 penduduk maka terjadi kelahiran 31 . (Kecamatan Kedungkandang Dalam Angka 2018). 
Berdasarkan permasalahan tersebut, maka kajian studi penelitian ini yaitu mengenai jumlah anak yang dilahirkan pada wanita pasangan usia subur khususnya untuk mengetahui faktorfaktor yang mempengaruhi jumlah anak yang dilahirkan di Kelurahan Kotalama. Dari permasalahan tersebut variabel yang digunakan dalam penelitian ini yaitu pendidikan, pendapatan dan usia kawin pertama pasangan usia subur. Todaro (2006), yang menyatakan bahwa semakin tinggi tingkat pendidikan istri atau wanita cenderung untuk merencanakan jumlah anak yang semakin sedikit. Keadaan ini menunjukkan bahwa wanita yang telah mendapatkan pendidikan lebih baik cenderung memperbaiki kualitas anak dengan cara memperkecil jumlah anak. Seseorang yang memiliki status pendidikan yang tinggi pada umumnya akan menunda pernikahannya karena lebih berorientasi pada pendidikan dan pekerjaan yang layak (Ananta, 1993), sehingga dalam hal ini akan di uji secara rinci.

Bollen Kenneth AJ et.al (dalam Suandi, 2002) menunjukkan bahwa pekerjaan kepala rumah tangga atau sang suami merupakan indikator dari penghasilan dan fertilitas, dengan kata lain status pekerjaan suami berpengaruh positif terhadap penghasilan kemudian melalui penghasilan inilah berpengaruh negatif dengan fertilitas. Pekerjan suami yng berimbas pada endapatan sedikit banyak akan mempengaruhi keputusan untuk memiliki anak

Badan Pusat Statistik mendefinisikan usia kawin pertama sebagai umur pertama kawin yang berarti juga saat dimulainya masa reproduksinya pembuahan. Semakin muda usia kawin pertama maka akan semakin panjang masa reproduksinya atau semakin banyak anak yang dilahirkan.

seberapa variabel yang diugunakan dipilih karena hal tersebut merupakan beberapa hal yang cukup berpengaruh (berdasarkan literature review dari jurnal riset sebelumnya yang terpublikasi), mempertimbangkan bahwasannya beberapa variabel yang digunakan memiliki banyak referensi dan hasil yang telah dilakukan oleh penelitian yang telah dilakukan sebelumnya

\section{METODE}

Dalam penelitian ini, menggunakan metode kuantitatf yaitu proses penggalian informasi yang diwujudkan dalam bentuk angka-angka yang diolah secara statistik. Penelitian kuantitatif adalah penelitian yang memiliki permasalahan yang jelas. Berdasarkan latar belakang dan rumusan masalah yang telah disebutkan, penelitian ini menggunakan pendekatan korelasi (Sugiyono, 2014). Pendekatan korelasi ini yaitu pendekatan sebab akibat yang tujuannya untuk mengetahui hubungan antara variabel bebas (pendapatan, Pendidikan dan usia kawin pertama) yang dalam hal ini menggunakan skala data dengan variabel terikat (jumlah anak lahir hidup). Data yang digunakan adalah data primer dan sekunder. Data primer diperoleh dari metode wawancara, dokumentasi dan observasi di lapangan. Data yang diperoleh dari wawancara adalah mengenai pendidikan istri, pendapatan total keluarga, penggunaan $\mathrm{KB}$ dan usia kawin pertama istri. Data sekunder diperoleh dari pengumpulan data dari berbagai sumber pendukung. (Tabel 1). Berikut merupakan tabel jenis data yang digunakan:

Tabel 1. Jenis skala data yang digunakan

\begin{tabular}{|c|c|c|c|c|}
\hline Variabel & Indikator & $\begin{array}{c}\text { Sumber } \\
\text { Data }\end{array}$ & Jenis Data & Analisis Data \\
\hline \multicolumn{5}{|l|}{ Variabel Terikat (y) } \\
\hline Jumlah Anak & Jumlah anak lahir & Primer & Rasio & \\
\hline (Fertilitas) & hidup & & & Tabulasi Tunggal, \\
\hline Variabel Bebas (x) & & & & Tabulasi Silang dan Uji \\
\hline Pendapatan & $\begin{array}{l}\text { Jumlah pendapatan } \\
\text { perbulan(rupiah) }\end{array}$ & Primer & Rasio & Regresi Linier Berganda \\
\hline Usia kawin & $\begin{array}{l}\text { Umur kawin pertama } \\
\text { ibu }\end{array}$ & Primer & Rasio & \\
\hline Pendidikan & Tahun sukses ibu & Primer & Rasio & \\
\hline
\end{tabular}

Penelitian ini dilakukan di Kelurahan Kotalama Kecamatan Kedungkandang Kota Malang.Pengolahan data menggunakan analisis tabulasi tunggal, tabulasi silang dan uji regresi linier berganda. Jumlah populasi dalam penelitian ini sebesar 9.223 wanita pasangan usia subur yang telah menikah dan melahirkan, kemudian dalam menentukan jumlah sampel menggunakan rumus Slovin (Ageng Wahyudin, 2016). Jumlah keseluruhan sampel penelitian adalah 98. Dalam menentukan jumlah sampel responden tiap RW menggunakan Teknik 
pengambilan sampel proporsional random sampling dengan rumus sebagai berikut.

Keterangan :

$$
n A=\frac{n}{N} x N A
$$

$$
\begin{array}{ll}
\mathrm{nA} & \text { : ukuran sampel per RW } \\
\mathrm{n} & \text { : ukuran sampel } \\
\mathrm{N} & \text { : ukuran populasi } \\
\mathrm{NA} & \text { : ukuran populasi per RW }
\end{array}
$$

Berikut merupakan perhitungan menentukan jumlah sampel menggunakan rumus slovin : $n A=\frac{98}{9223} \times 816=9$
$n A=\frac{9223}{1+9223\left(0,10^{\wedge} 2\right)} \times 816=9$

Tabel 1. Sampel Penelitian di Kelurahan Kotalama Tahun 2019

\begin{tabular}{cccc}
\hline No & RW & PUS & n \\
\hline 1 & RW 1 & 816 & 9 \\
2 & RW 2 & 688 & 7 \\
3 & RW 3 & 643 & 7 \\
4 & RW 4 & 564 & 6 \\
5 & RW 5 & 521 & 6 \\
6 & RW 6 & 860 & 9 \\
7 & RW 7 & 981 & 10 \\
8 & RW 8 & 712 & 8 \\
9 & RW 9 & 778 & 8 \\
10 & RW 10 & 1.287 & 14 \\
11 & RW 11 & 1.373 & 15 \\
\hline \multicolumn{2}{c}{ Jumlah } & 9.223 & 98 \\
\hline
\end{tabular}

\section{HASIL DAN PEMBAHASAN}

\section{Jumlah Anak Lahir Hidup}

Jumlah anak lahir hidup dalam penelitian ini adalah banyaknya jumlah anak yang dilahirkan oleh PUS (pasangan usia subur) di Kelurahan Kotalama Kecamatan Kedungkandang Kota Malang. Jumlah anak lahir hidup pada penelitian ini memiliki rentang satu sampai dengan enam anak yang dimaksud adalah banyaknya anak yang lahir dalam kondisi hidup yang dimiliki wanita pasangan usia subur.

Berdasarkan Tabel 2 dapat diperoleh gambaran mengenai jumlah anak lahir hidup yang dimiliki wanita pasangan usia subur yang telah menikah dan melahirkan anak. Sebagian besar memiliki jumlah anak lahir hidup dua anak sebanyak 45 responden atau sebesar 45,92\% dari 98 responden. Sementara responden terendah terdapat pada jumlah anak lahir hidup enam anak sebanyak tiga responden atau 3,06\%. Rata-rata jumlah anak lahir hidup yang dimiliki wanita pasangan usia subur yang telah menikah dan melahirkan anak adalah 2,46 artinya rata-rata jumlah anak lahir hidup yang dimiliki wanita pasangan usia subur berkisar antara dua sampai dengan tiga anak. Rata-rata jumlah anak lahir hidup pada wanita pasangan usia subur sudah mendekati keluarga ideal. Untuk memperjelas

\begin{tabular}{|c|c|c|c|}
\hline No & Anak Lahir Hidup (x) & f & $\%$ \\
\hline 1 & 1 & 16 & 16,33 \\
\hline 2 & 2 & 45 & 45,92 \\
\hline 3 & 3 & 23 & 23,47 \\
\hline 4 & 4 & 7 & 7,14 \\
\hline 5 & 5 & 4 & 4,08 \\
\hline \multirow[t]{2}{*}{6} & 6 & 3 & 3,06 \\
\hline & Rata -Rata & 2,46 & \\
\hline
\end{tabular}
disajikan dalam bentuk peta dapat dilihat pada Gambar 1.

Tabel 2. Jumlah Anak Lahir Hidup di Kelurahan Kotalama 2019

\section{Faktor yang Mempengaruhi Jumlah Anak} Lahir Hidup

1. Perbedaan Jumlah Anak Lahir Hidup Berdasarkan Pendidikan

Tabel 3 merupakan rata-rata tingkat pendidikan yang diselesaikan oleh responden secara keseluruhan dan rata-rata jumlah anak yang dimiliki. Pendidikan yang paling mendominasi adalah menengah kebawah atau termasuk pendidikan yang masih rendah (Tidak sekolah, SD/MI dan SMP/MTS). Sementara untuk responden dengan tingkat pendidikan SMA tidak ada yang memiliki anak lahir hidup lebih dari tiga atau empat anak.

Tabel 3 menunjukkan bahwa hanya wanita dengan pendidikan akhir SD dan SMP yang memiliki jumlah anak lahir hidup hingga 6 anak. Rata-rata jumlah anak lahir hidup paling banyak berada pada wanita dengan pendidikan SMP yaitu sebanyak 2 anak. Hal ini dapat mengindikasikan bahwa semakin rendah pendidikan wanita PUS maka semakin banyak jumlah anak yang dilahirkan.

2. Perbedaan Jumlah Anak Lahir Hidup

Berdasarkan Pendapatan Keluarga

Pendapatan keluarga merupakan salah satu faktor yang dapat mempengaruhi jumlah anak yang dilahirkan. Di Kelurahan Kotalama, masyarakat mayoritas bekerja sebagai pedagang. Tetapi jenis barang yang dijual berbeda-beda, sehingga pendapatan yang diperoleh tidak sama.

Pada Tabel 4 diketahui bahwa rata-rata terbesar jumlah anak lahir hidup terhadap pada keluarga dengan pendapatan total $\geq 6.026 .000$ yaitu 4,00. Hal ini menandakan Hal ini dapat dikatakan bahwa semakin rendah pendapatan maka semakin tinggi jumlah anak yang dilahirkan. 
Tabel 3. Perbedaan Jumlah Anak Lahir Hidup Berdasarkan Pendidikan Istri di Kelurahan Kotalama Tahun 2019

\begin{tabular}{|c|c|c|c|c|c|c|c|c|c|}
\hline \multirow{3}{*}{ No. } & \multirow{3}{*}{ Pendidikan } & \multicolumn{6}{|c|}{ Jumlah Anak Lahir } & \multirow{3}{*}{ Jumlah } & \multirow{3}{*}{ Rata-Rata } \\
\hline & & 1 & 2 & 3 & 4 & 5 & 6 & & \\
\hline & & $\mathbf{f}$ & f & $\mathbf{f}$ & f & f & f & & \\
\hline 1 & SD & 8 & 17 & 15 & 5 & 2 & 1 & 48 & 2,56 \\
\hline 2 & SMP & 2 & 13 & 6 & 1 & 2 & 2 & 26 & 2,77 \\
\hline 3 & SMA & 5 & 15 & 2 & 0 & 0 & 0 & 22 & 1,86 \\
\hline 4 & Tidak Sekolah & 1 & 0 & 0 & 1 & 0 & 0 & 2 & 2,5 \\
\hline
\end{tabular}

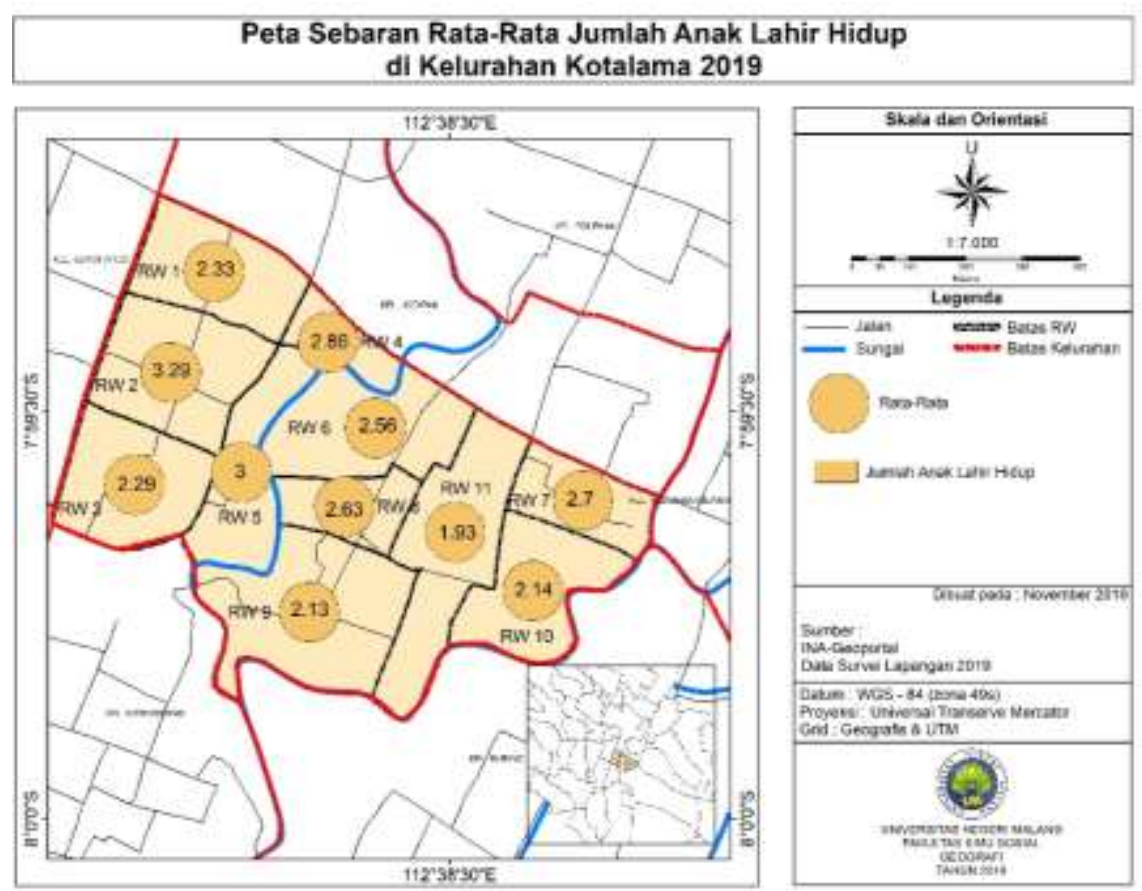

Gambar 1. Peta Sebaran Rata-Rata Jumlah Anak Lahir Hidup (Persentase jumlah anak lahir hidup)

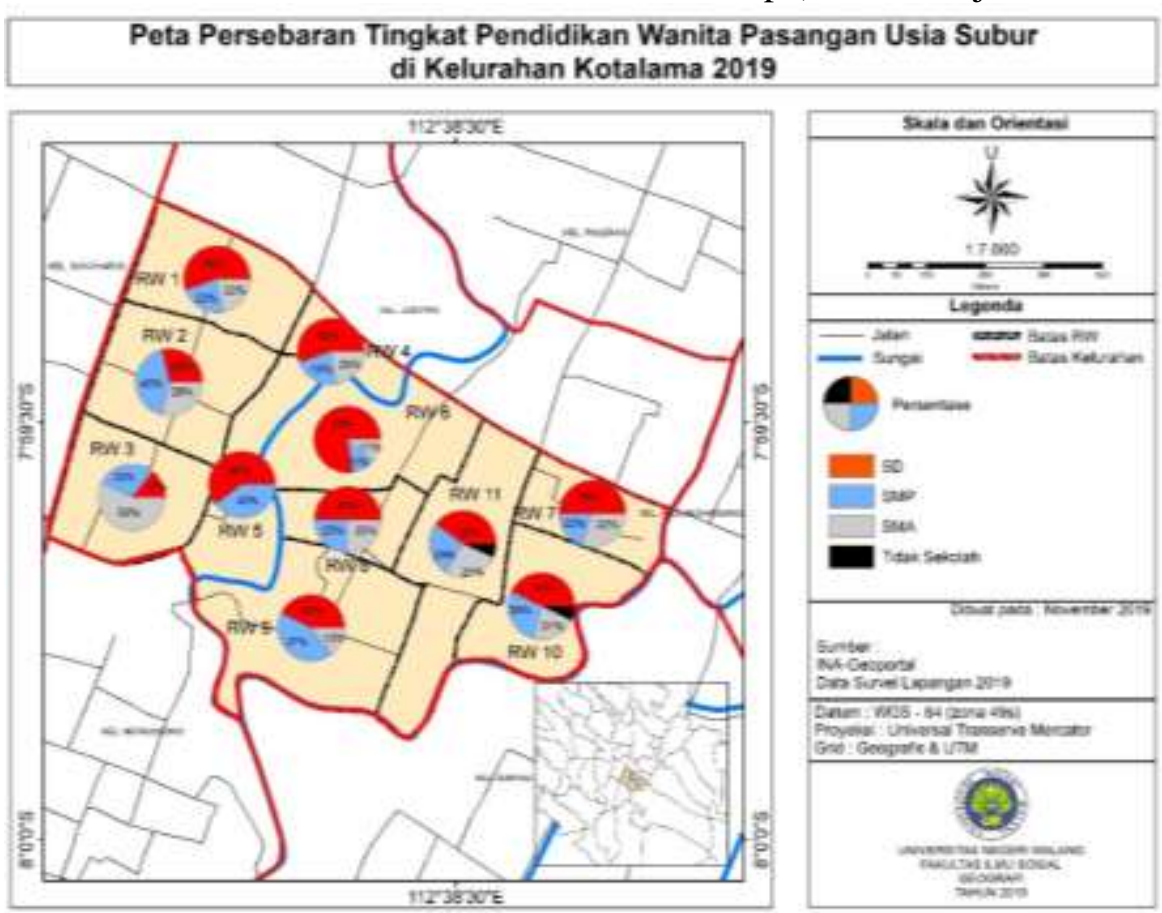

Gambar 2. Peta Sebaran Tingkat Pendidikan (Persentase tingkat pendidikan wanita PUS) 
3. Perbedaan Jumlah Anak Lahir Hidup

Berdasarkan Usia Kawin Pertama Istri

Usia kawin pertama merupakan usia pertama kali seseorang melakukan pernikahan. Usia ideal untuk menikah menurut BKKBN adalah usia 21 bagi wanita dan usia 25 bagi pria. Mayoritas masyarakat Kelurahan Kotalama menikah di usia dini. Wanita yang menikah di usia dini cenderung melahirkan jumlah anak yang lebih banyak dibandingkan dengan wanita yang menikah pada usia ideal karena alasan, semakin pendeknya masa reproduksi.

Pada Tabel 5 dapat diketahui bahwa istri yang menikah di bawah 20 tahun cenderung melahirkan anak lebih dari dua. Responden yang menikah pada rentang usia dibawah 20 tahun memiliki jumlah anak lahir hidup mulai dari satu hingga enam anak. Hal ini dapat dikatakan bahwa semakin rendah usia kawin pertama maka semakin tinggi jumlah anak yang dilahirkan.

Tabel 4. Perbedaan Jumlah Anak Lahir Hidup Berdasarkan Pendapatan Keluarga di Kelurahan Kotalama Tahun 2019

\begin{tabular}{|c|c|c|c|c|c|c|c|c|c|}
\hline \multirow{3}{*}{ No. } & \multirow{3}{*}{$\begin{array}{c}\text { Pendapatan } \\
\text { (Rupiah) }\end{array}$} & \multicolumn{6}{|c|}{ Jumlah Anak Lahir } & \multirow{3}{*}{ Jumlah } & \multirow{3}{*}{$\begin{array}{l}\text { Rata- } \\
\text { Rata }\end{array}$} \\
\hline & & 1 & 2 & 3 & 4 & 5 & 6 & & \\
\hline & & f & f & $\mathbf{f}$ & f & $\mathbf{f}$ & $\mathbf{f}$ & & \\
\hline 1 & $\leq 2.675 .000$ & 11 & 18 & 9 & 3 & 2 & 1 & 44 & 2,32 \\
\hline 2 & $2.676 .000-4.350 .000$ & 3 & 23 & 11 & 4 & 1 & 0 & 42 & 2,45 \\
\hline 3 & $4.351 .000-6.025 .000$ & 2 & 3 & 3 & 0 & 1 & 1 & 10 & 2,80 \\
\hline 4 & $\geq 6.026 .000$ & 0 & 1 & 0 & 0 & 0 & 1 & 2 & 4,00 \\
\hline
\end{tabular}

Tabel 5. Perbedaan Jumlah Anak Lahir Hidup Berdasarkan Pendapatan Keluarga di Kelurahan Kotalama Tahun 2019

\begin{tabular}{|c|c|c|c|c|c|c|c|c|c|}
\hline \multirow{3}{*}{ No. } & \multirow{3}{*}{ Usia Kawin Pertama } & \multicolumn{6}{|c|}{ Jumlah Anak Lahir } & \multirow{3}{*}{ Jumlah } & \multirow{3}{*}{$\begin{array}{l}\text { Rata- } \\
\text { Rata }\end{array}$} \\
\hline & & 1 & 2 & 3 & 4 & 5 & 6 & & \\
\hline & & $\mathbf{f}$ & f & $\mathbf{f}$ & f & f & f & & \\
\hline 1 & $\begin{array}{l}\text { Pernikahan Dini } \\
\text { ( } \leq 20 \text { Tahun) }\end{array}$ & 8 & 24 & 18 & 7 & 4 & 3 & 64 & 2,75 \\
\hline 2 & $\begin{array}{l}\text { Pernikah Ideal } \\
\text { ( } \geq 21 \text { Tahun) }\end{array}$ & 8 & 21 & 5 & 0 & 0 & 0 & 34 & 1,91 \\
\hline
\end{tabular}

\section{Uji Regresi Linier Berganda}

Uji regresi linier digunakan untuk menguji pengaruh pendidikan istri, pendapatan total keluarga dan usia kawin pertama istri terhadap jumlah anak lahir hidup. Terdapat dua uji yang akan dilakukan dengan menggunakan uji regresi linier berganda diantaranya uji t dan uji $\mathrm{F}$.

1. Uji t (Uji Parsial)

Pengujian ini digunakan untuk mengukur pengaruh tingkat signifikansi secara parsial antara variabel bebas (pendidikan istri, pendapatan total keluarga dan usia kawin pertama istri) terhadap variabel terikat (jumlah anak lahir hidup ). Dalam menggunakan uji t ini, diperlukan adanya hipotesis dan kriteria pengujian. Adapun hipotesis penelitian yang digunakan dalam penelitian ini adalah sebagai berikut:

a. Ho :Terdapat pengaruh yang signifikan antara variabel bebas terhadap variabel terikat.

b. Ha :Tidak terdapat pengaruh yang signifikan antara variabel bebas terhadap variabel terikat.

Kriteria pengujian yang digunakan dalam penelitian ini adalah sebagai berikut: a. Ho ditolak dan Ha diterima apabila nilai signifikansi (Sig) $<\alpha=0,05$

b. Ho diterima dan Ha ditolak apabila nilai signifikansi (Sig) $>\alpha=0,05$

Variabel pendidikan istri (X1), nilai signifikansinya adalah 0,629 , nilai ini lebih besar dari pada $\alpha=0,05$, sehingga dapat dikatakan bahwa faktor pendidikan istri (X1) tidak berpengaruh signifikan terhadap jumlah anak yang dilahirkan hidup (Y). Variabel pendapatan total keluarga (X2), nilai signifikansinya adalah 0.02 , nilai ini lebih kecil dari pada $\alpha=0,05$, sehingga dapat dikatakan bahwa faktor pendapatan total keluarga (X2) berpengaruh signifikan terhadap jumlah anak yang dilahirkan hidup (Y). Variabel usia kawin pertama istri (X3), nilai signifikansinya adalah 0,00 , nilai ini lebih kecil dari pada $\alpha=0,05$, sehingga dapat dikatakan bahwa faktor usia kawin pertama istri (X3) berpengaruh signifikan terhadap jumlah anak yang diinginkan (Y).

2. Uji F (Uji Simultan)

Pengujian ini digunakan untuk mengukur pengaruh tingkat signifikansi secara bersama antara variabel bebas (pendidikan istri, pendapatan total keluarga dan usia kawin 
pertama istri) terhadap variabel terikat (jumlah anak lahir hidup). Kriteria pengujiannya adalah jika nilai sig $<0,05$ maka terdapat pengaruh yang signifikan, sedangkan jika nilai sig >0,05 maka tidak ada pengaruh yang signifikan

Pada hasil uji $\mathrm{F}$ diperoleh, dapat diketahui bahwa nilai $\mathrm{F}$ hitung sebesar 7.158 dan nilai signifikansinya sebesar 0,000 , nilai signifikansi ini lebih kecil daripada nilai $\alpha=0,05$. Menurut Ghozali (2011) jika nilai sig < 0,05 maka variabel independent (X) secara simultan berpengaruh terhadap variabel dependent $(\mathrm{Y})$. Dengan demikian dapat diartikan bahwa variabel bebas (pendidikan istri, pendapatan total keluarga dan usia kawin pertama istri) secara bersama berpengaruh signifikan terhadap variabel terikat (jumlah anak lahir hidup).

\section{Koefisien Determinasi $\left(\mathrm{R}^{2}\right)$}

Koefisien Determinasi ( $R$ Square atau $\mathrm{R}^{2}$ ) merupakan salah satu hasil dari uji regresi linier berganda yang digunakan untuk mengetahui seberapa besar atau berapa persen (\%) variabel bebas dapat mempengaruhi variabel terikat.

Tabel 8 menunjukkan bahwa nilai koefisien determinasi atau $R$ square adalah sebesar 0,188. Nilai $R$ Square ini berasal dari pengkuadratan nilai R. Besarnya angka koefisien deterinasi $(R$ Square) 0,188 atau sama dengan $18,8 \%$. Angka $18,8 \%$ mengandung arti bahwa variabel bebas secara simultan (bersama-sama) berpengaruh terhadap variabel terikat sebesar $18,8 \%$ sedangkan sisanya dipengaruhi oleh variabel lain yang tidak diteliti.

Tabel 6. Hasil Uji T Parsial

\begin{tabular}{lccccc}
\hline \multicolumn{1}{c}{ Model } & $\begin{array}{c}\text { Unstandarized } \\
\boldsymbol{B}\end{array}$ & $\begin{array}{c}\text { Coefficient Std. } \\
\text { Error }\end{array}$ & $\begin{array}{c}\text { Standarized } \\
\text { Coefficient Beta }\end{array}$ & $\mathbf{t}$ & Sig \\
\hline (Constant) & 4.890 & 0.812 & & 6.025 & 0.000 \\
Tingkat Pendidikan (X1) & 0.029 & 0.060 & 0.51 & 0.485 & 0.629 \\
Pendapatan (X2) & 0.000 & 0.000 & 0.220 & 2.324 & 0.022 \\
Usia kawin (X3) & -0.165 & 0.042 & -0.410 & -3.896 & 0.000 \\
\hline
\end{tabular}

Tabel 7. Hasil Uji F Simultan

\begin{tabular}{llcccc}
\hline Model & Sum of Squares & $\boldsymbol{d} \boldsymbol{c}$ & Mean Square & F & Sig \\
\hline Regresion & 38.690 & 3 & 12.897 & 7.158 & $0.000^{\mathrm{b}}$ \\
Residual & 167.558 & 93 & 1.802 & & \\
Total & 206.247 & 96 & & & \\
\hline a. & Dependent variable $:$ Jumlah anak lahir hidup (Y) & & &
\end{tabular}

Tabel 8. Hasil Nilai Koefisien Determinasi

\begin{tabular}{cccccc}
\hline Model & $\mathbf{R}$ & $\boldsymbol{R}$ Squre & $\begin{array}{c}\text { Adjusted } \boldsymbol{R} \\
\text { Square }\end{array}$ & $\begin{array}{c}\text { Std. Error of } \\
\text { the Estimate }\end{array}$ & $\begin{array}{c}\text { Durbin - } \\
\text { Watson }\end{array}$ \\
\hline 1 & $0.433^{\mathrm{a}}$ & 0.188 & 0.161 & 1.342 & 1.605 \\
\hline
\end{tabular}

a. Dependent variable : Jumlah anak lahir hidup (Y)

\section{SIMPULAN DAN SARAN}

\section{Simpulan}

Berdasarkan penelitian yang dilakukan, dapat disimpulkan bahwa tidak terdapat pengaruh antara tingkat pendidikan terhadap jumlah anak lahir hidup wanita pasangan usia subur yang telah menikah dan memiliki anak. Rata-rata jumlah anak lahir hidup berdasarkan tingkat pendidikan terbesar pada jenjang SMP/MTS. Sedangkan pendidikan SD/MTS memiliki rata-rata yang lebih kecil.

Terdapat pengaruh antara pendapatan total keluarga terhadap jumlah anak lahir hidup wanita pasangan usia subur. Pendapatan total keluarga yang cenderung tinggi memiliki jumlah anak lahir hidup yang lebih kecil. Rata-rata jumlah anak lahir hidup terendah berdasarkan pendapatan total keluarga pada keluarga yang berpendapatan rendah. Terdapat pengaruh antara usia kawin pertama terhadap jumlah anak lahir hidup yang dimiliki wanita pasangan usia subur. Wanita usia subur yang menikah di usia dini cenderung memiliki jumlah anak lahir hidup yang besar. Dibandingkan wanita yang menikah diusia ideal. Rata-rata jumlah anak lahir hidup tertinggi berada pada wanita usia subur yang menikah diusia dini

\section{Saran}

1. Pemerintah harus lebih memperhatikan wilayah yang memiliki kepadatan yang tinggi, khususnya Kelurahan Kotalama. Di Kelurahan Kotalama banyak rumah yang 
tidak layak untuk dihuni, juga terdapat rusun. Juga rendahnya sosialisasi tentang KB tidak menyeluruh kepada masyarakat yang ada di Kelurahan Kotama. Oleh karena itu diperlukan sosialisasi tentang KB untuk menekan angka kelahiran di Kelurahan Kotalama

2. Masyarkat Kelurahan Kotalama sebaiknya memperhatikan kondisi demografi yang ada, dimana daerah yang mereka tinggali memiliki penduduk yang sangat padat dan memperhatikan Pendidikan anak agar orang tua harus menekankan pada kualitas anak agar menjadi orang yang berguna.

3. Peneliti ini hanya berada pada lingkup Kelurahan saja, sehingga kajiannya tidak begitu luas dan tidak membandingkan kondisi sosial ekonomi antar keluarga satu dengan lainya. Oleh karenanya bagi peneliti selanjutnya dapat memperluas kajian wilayah penelitian agar memperoleh hasil yang lebih baik

\section{DAFTAR RUJUKAN}

1] Ananta, Aris. 1993. Ciri Demografi Kualitas Penduduk dan Pembangunan Ekonomi. Jakarta. Bina Aksara. Jakarta.

2] Anwar, Zainul. 2018. Faktor-faktor yang mempengaruhi jumlah anak yang diinginkan oleh pasangan usia subur (PUS) Di Wilayah Perdesaan Kecamatan Lumbang Dan Wilayah Perkotaan Kecamatan Bangil Kabupaten Pasuruan. Skripsi tidak diterbitkan. FIS UM.

3] Ageng, Wahyudin. 2016. Faktor yang Mempengaruhi Fertilitas di Kelurahan Tanjung Raya Kecamatan Kedamaian Kota Bandar Lampung. Skripsi. Universitas Bandar Lampung.

4] BKKBN. Pusat Badan Keluarga Berencana dan Pemberdayaan Masyarakat Kota Malang, 2016. Kota Malang. BKKBN

5] BPS. 2016. Perkawinan Usia Anak di Indonesia Tahun 2013-2015. Jakarta: BPS Indonesia

6] BPS. 2018. Kecamatan Kedungkandang Dalam Angka 2018. Kota Malang. BPS Kota Malang

7] GDPK. 2018. Penyusunan Grand Design Pembangunan Kependudukan Kota Malang. Dinas DP3AP2B Kota Malang.
8] Ghozali, Imam. 2011. Aplikasi Analisis Multivariate Dengan Progam SPSS. Semarang: Badan Penerbit Universitas Diponegoro.

9] Nisak, M. K. (2019). Studi Unmet Need KB Pada Perempuan Pasangan Usia Subur Di Kampung KB Pantai Selatan Tulungagung (Desa Kalibatur Kecamatan Kalidawir Kabupaten Tulungagung). SKRIPSI Jurusan Geografi-Fakultas Ilmu Sosial UM

10] Sugiyono. 2014. Metode Penelitian Kuantitatif Kualitatif dan $R \& D$. Bandung: Alfabeta.

11] Todaro, MP. 2006. Pembangunan Ekonomi Edisi Kesembilan. Erlangga, Jakarta. 